\title{
EFFECTS OF THE COMPUTER ADED INSTRUCTIONAL PACKAGE AND THREE DIMENSIONAL VISUALS ON THE PERFORMANCE OF SECONDARY SCHOOL STUDENTS IN BIOLOGY
}

\section{A. A. YAKI AND CHUKWU, NNENNAYA}

\begin{abstract}
This study aims to investigate the effects of the computer aided instructional package (CAIP) and three dimensional visuals on the performance of secondary school students in Biology. The design of this study is pretest posttest control group design. The participants of the study consist of 68 students; 24 in the experimental group 1,24 in the experimental group 2 and control group has 20. The experimental group 1 received instruction via the computer aided instructional package (CAIP), experimental group 2 receives instruction via three dimensional visual while the control group received instruction via the conventional method. The treatment lasted for four weeks. The instrument for data collection is Biology Achievement Test (BAT). The method of data analysis is one way analysis of variance (ANOVA) and t-test. The result of the study reveals that there is a statistically significant increase in the achievements of experimental group land experimental group 2 more than the control group. There were no gender effects in the two experimental groups. It was concluded that CAIP and three dimensional visual improve secondary school students' performance in biology. It was recommended among others that Workshop on production and utilization of instructional materials especially computer aided instructional packages and models should be organized for secondary school teachers.
\end{abstract}

\section{Introduction}

Biology is one of the most useful branches of science. Knowledge of Biology is very important in the st Idy and understanding of our body and environment. It has helped man to develop good ind proper health care habits in understanding the Epidemiology of various diseases, their prevention, control measures and treatment. Basic principles in the application of biology, especially in genetics, have helped in the choice of career, marriage partners etc. Biology is also important in pursuing careers in medicine, pharmacy, zoology, agriculture jusí to mention a few.

It is probably in recognition of this tremendous importance, that Biology is one of the three basic science subjects taught in Nigerian secondary schools. According to the National Policy on Education FRN, (2004) "every student shall take all the six (6) core subjects in group A and a minimum of one and a maximum of two (2) from the list of elective subjects in group $B$ and $C$ to give a minimum of seven (7) and a maximum of eight (8) subjects." One of Biology, physics, chemistry or health science is to be selected as a core subject. Hence, non science or art students commonly select and register Biology and reject others. It is the most favoured among other science subjects, 
considering the number of students that offer it in public examination (Danmole and Femi-Adeoye, 2004)

The human digestive system is complicated consisting of a very long tube with various parts starting from the mouth and ending at the anus. The following points on special features of the system: Mouth, tongue, salivary gland, pharynx, epiglottis, trachea, oesophagus, diaphragm, cardiac, sphincter, liver, spleen, stomach, pancreas, small intestine, duodenum, large intestine, caecum, appendix, rectum and anus. The parts of the alimentary canal are internally situated and can only be learnt effectively by using instructional materials such as Visual imagery.

Visual Imagery: This simply means representation, replica or copy of an object or event that can be seen and felt physically or conceptualized with the mind (Gbodi, 1999). With regards to teaching and learning Visual Imagery belongs to the category of Visual media such as graphics, Models, realia etc. Visual imagery can be divided into three dimensional visuals such as Models and Realia while, two dimensional such as pictures, graphs, maps etc. Ardac (2005) and Gbodi (1999), opined that visual information (models) is important and necessary in teaching and learning process. It enhance comprehension and effectiveness in aiding memory. Hence the use of models in teaching and learning could solve instructional problems especially where concepts are abstract and difficult to understand.

MODEL: This is a three dimensional Visual usually on a smaller scale. They can be seen as ideas, expressions, diagrams, concrete objects through which realities can be represented, communicated and appreciated in educational instruction. Models can be used to highlight important details in such a way that the real thing may not (Gbodi, 2005). Adeghenro (2006) investigated the effectiveness of instructional models in teaching and learning of mathematics at junior secondary schools in Minna, Niger state, Nigeria. His result shows that Instructional model is a better approach to embark on by mathematics teachers for meaningful learning than lecture method. Also, the findings of Oluyemi (2008), Yaki (2006) and Ighoyovwi (2008) corroborated this. In their separate studies in biology, they found that instructional models enhance effective learning and performance among secondary school students in biology. Hence, results indicated that teaching through models was more effective than the traditional teaching techniques in the learning of science. Contrary to this, Ibrahim (2008) found that there is no significant difference between students taught human digestive system using a model and those taught using the traditional teaching method

Computer-assisted instructional package (CAIP) plays an important role in contemporary teaching and learning of science concepts (Chang, 2001). Besides, it is evident that for effective use of computers in science classroom, Computer Aided Instructional materials (CAIMs) need to be developed. The use of computer technology enables learners to be active in the learning process, to construct knowledge, to develop problem solving skills and to discover alternative solutions (Özmen, 2008). Educational technologies, especially computers, play an important role in concretizing abstract concepts, which are difficult for children to learn, by means of animations (Akpınar, 2005 \& Fagbemi, Gambari, Oyedum \& Gbodi, 2011) 
Several research studies have revealed that CAIP improved student's academic performance in science than traditional teaching methods which involve teacher presentation. (Wilder, 2006; Liao, 2007; Ragasa, 2008; Hançer \& Yalçın, 2009;). Contrary to the above findings some studies shows that there is no significant difference in the academic performance of students exposed to CAI and those exposed to traditional teaching methods (Bayraktar, 2001; Alacapınar, 2003; Çetin, 2007).

Gender has been linked to students' academic performance in science and there has been no definite conclusion on the findings on gender as it affects students' performance (Gambari, 2010). The findings of Ibrahim (2008), Olatunji (2008), Olowe (2009) and Wushishi and Chado (2010) showed that there is no gender effect on the academic performance of male and female students in science concepts. Contrary to these findings other researchers found that male students perform better than their female counterpart in science and mathematics concepts (Njoku, 2002 and Yaki 2011).

\section{Statement of the Problem}

Available statistics from West African Examination Council (WAEC) on senior secondary school students' performance in biology reveal that, biology has the highest number of enrolment compared to other science subjects. Students' performance in the subject is very poor. This poor performance by students if not checked will impede the achievement of vision 20: 2020 as well as the aims and objectives of education in Nigeria which states that "education should aim at helping the child achieve appropriate skills, abilities and competences, both mental and physical as equipment for the individual to live and contribute to the development of his society" (FME 2004).

A number of factors responsible for students poor performance in biology have been identified which include; lack of instructional materials and science equipment (Shaliu 2004; Yusuf, 2004), and use of traditional method of teaching (Biodun 2004 \& Bajah 2010). Many science teachers prefer the traditional method of teaching which is mainly a verbal exercise and teacher centred, while learners are passive listeners. The teachers tend to shy away from activity based and learner centred instructional strategies. The new trend in teaching science in the $21^{\text {st }}$ century favours the application of computer in teaching and learning such as computer aided instructional package (CAIP) and other audio visual materials.

Considering gender as a moderating variable in this study can yield useful information. Findings on gender as it relate to achievement in science is inconclusive The findings of Olowe (2009) and Wushishi and Chado (2019) showed that there is no gender effect on the academic performance of male and female students in science concepts. Contrary to these findings other researchers found that male students perform better than their female counterpart in science and mathematics concepts (Njoku, 2002 and Yaki 2011). Hence, the need to consider gender as a moderating viable

\section{Objective of the Study}

The objectives of the study are to find out: 
(1) The difference in the performance of secondary school students in Biology when exposed to computer assisted instructional package, three dimensional and conventional method

(2) The influence of students' gender on their performance in biology, when they are exposed to computer aided instructional package and three dimensional visual

(3) The influence of students' gender on their performance in biology, when they are exposed to three dimensional visual

\section{Research Questions}

To guide the investigation the following research questions were stated;

1. Will there be any difference in the performance of secondary school students in biology when exposed to Computer-Assisted Instruction Package, three dimensional visuals and conventional method?

2. Does gender influence the performance of secondary school students in biology when exposed to computer-assisted instruction package?

3. Does gender influence the performance of secondary school students in biology when exposed to three dimensional visual?

\section{Research Hypotheses}

The following research hypotheses were formulated and tested in the study.

$\mathrm{Ho}_{1}$ : There is no significant difference in the performance of secondary school students in biology when exposed to computer-assisted instruction package, three dimensional visuals and conventional method

$\mathrm{Ho}_{2}$ : There is no significant gender difference in the performance of secondary school students in biology when exposed to computer-assisted instruction package

Ho3: There is no significant gender difference in the performance of secondary school students in biology when exposed to three dimensional visual.

\section{Methodology}

The research design was a pretest posttest control group design. The population was all senior secondary school students in Minna metropolis. The sample for this study was randomly drawn from three comparable co-educational secondary schools in Minna metropolis. Preliminary investigation showed that the schools were comparable in terms of academic standard, method of student's admission, recruitment of teachers, physical facilities and science laboratory equipment and materials. The subject of this study are 68 senior secondary school students (SSS2) who were systematically drawn and assigned into experimental group $1,(n=24)$. Students in this group were instructed with computer aided instructional package (CAIP). Experimental group 11, $(\mathrm{n}=24)$. Students in experimental group were instructed with an improvised model on the biology content while the students in the control group $(n=20)$ were taught using the conventional method 
The instrument for this study was Biology Achievement Test (BAT). The (BAT) is composed of 25 item multiple choice questions which cover: Ingestion, Digestion, Absorption, Structure of the Alimentary canal and Egestion. The Biology Achievement Test objective questions were validated by two science lecturers and one senior Biology teacher in secondary school. The reliability of the instrument was found to be 0.78 .

The study lasted for five weeks, the experimental group 1, experimental group 11 and control groups were given BAT as pretest at the beginning of the study. Both groups received treatment. At the end of the treatment, both groups were administered BAT as post-test. The method of data analysis was t-test and ANOVA.

Results

The finding of this study are presented and explained in tables below:

Hypothesis one $\left(\mathrm{Ho}_{1}\right)$ There is no significant difference in the performance of secondary school students in Biology when exposed to computer-assisted instruction package, three dimensional visuals and conventional method

To determine this hypothesis, one way ANOVA and Schefe multiple comparison was used, the result is as shown in Table $1 \mathrm{a}$ and $1 \mathrm{~b}$.

Table 1a: ANOVA comparison of the three groups' Experimental group 1, Experimental group 2 and the control.

\begin{tabular}{llllll}
\hline Source of variation & & \multicolumn{3}{l}{ Mean } \\
& Sum of Squares & Df & Square & F & Sig. \\
\hline Between Groups & 490.784 & 2 & 245.392 & $6.778^{*}$ & .002 \\
Within Groups & 2353.333 & 65 & 36.205 & & \\
Total & 2844.118 & 67 & & & \\
\hline
\end{tabular}

*Significant at $\mathrm{p}<0.05$

Table1b: Schefe Multiple Comparisons results of Experimental group 1, experimental group 2 and control

\begin{tabular}{|c|c|c|c|c|c|c|}
\hline \multirow[b]{2}{*}{ (I) Grp } & \multirow[b]{2}{*}{ (J) Grp } & \multirow{2}{*}{$\begin{array}{l}\text { Mean } \\
\text { Difference (I-J) }\end{array}$} & \multirow[b]{2}{*}{ Std. Error } & \multirow[b]{2}{*}{ Sig. } & \multicolumn{2}{|c|}{ 95\% Confidence Interval } \\
\hline & & & & & Lower Bound & Upper Bound \\
\hline \multirow[t]{2}{*}{1} & 2 & $5.833^{*}$ & 1.737 & .006 & 1.48 & 10.18 \\
\hline & 3 & $5.333^{*}$ & 1.822 & .018 & .77 & 9.90 \\
\hline \multirow[t]{2}{*}{2} & 1 & $-5.833^{*}$ & 1.737 & .006 & -10.18 & -1.48 \\
\hline & 3 & -.500 & 1.822 & .963 & -5.06 & 4.06 \\
\hline 3 & 1 & $-5.333^{*}$ & 1.822 & .018 & -9.90 & -.77 \\
\hline
\end{tabular}


2

.500

1.822

$.963-4.06$

5.06

Table 1a presents the ANOVA results of experimental group1, experimental group 2 and control. The results showed that there is a significant difference in the performance of students in the two experimental group and the control ( $\mathrm{Fca} 1=6.778, \mathrm{df}=67 ; \mathrm{p}<0.05$ ). Scheffes analysis on table $1 \mathrm{~b}$ indicated that the observed significant difference was between experimental group 1 and experimental group 2 with the highest mean score of 5.833 and highest upper boundary of 10.18 at $95 \%$ confidence level. On this basis hypothesis one is rejected.

Ho2. There is no significant gender difference in the performance of secondary school students in biology when exposed to computer-assisted instruction package.

To determine the effect of gender on the performance of secondary school students in Biology exposed to computer-assisted instruction package (experimental 1).

Table 2: t-test comparison of the posttest mean score of Male and Female students of the experimental group 1

\begin{tabular}{llllllll}
\hline Variable & $\mathrm{N}$ & $\mathrm{Df}$ & $\mathrm{X}$ & $\mathrm{SD}$ & $\mathrm{t}$-value & $\mathrm{P}$ & Remarks \\
\hline male & 12 & & 63.75 & 7.11 & $0.81^{\text {ns }}$ & 0.44 & Not Significant \\
Female & 12 & 11 & 62.92 & 5.42 & & & \\
\hline
\end{tabular}

Ns = not significant $\mathrm{P}>0.05$

Table two indicates the posttest mean score of male and female students in the experiment group 1. The posttest means score is 63.75 for the male students and 62.92 for the female group. The male score did not differ significantly from the female scores when both were taught the digestive system using CAIP $(t=0.81 ; p>0.05)$. This shows that there is no significant difference between the posttest mean score of male and female students. Therefore, the null hypothesis is accepted.

Ho $:$ There is no significant gender difference in the performance of secondary school students in biology when exposed to three dimensional visual

To test for this hypothesis, t-test was use to determine the significant difference between the male and female students.

Table 3: t-test comparison of the posttest mean score of Male and Female students of the experimental group 2

\begin{tabular}{lccccccl}
\hline Variable & $\mathrm{N}$ & $\mathrm{Df}$ & $\mathrm{X}$ & $\mathrm{SD}$ & $\mathrm{t}$-value & $\mathrm{P}$ & Remarks \\
\hline Male & 12 & 11 & 57.08 & 4.50 & $0.69^{\mathrm{ns}}$ & 0.55 & Not Significant
\end{tabular}


Effects of the Computer Aided Instructional Package and Three Dimensional Visuals on the Performance of Secondary School Students in Biology

\begin{tabular}{llll}
\hline Female & 12 & 57.92 & 6.20
\end{tabular}

Ns not significant $\mathrm{P}>0.05$

Table three indicates the posttest mean score of male and female students in the experiment group 2. The posttest mean scores are 57.08 for the male students and 57.92 for the female group. The male score did not differ significantly from the female scores when both were taught genetics using guided inquiry in a cooperative setting, $(t=0.69 ; p$ $>0.05$ ). This shows that there is no significant difference between the posttest mean score of male and female students. Therefore, the null hypothesis is accepted.

\section{Findings of the study}

The major findings of the study were:

(i) There is significant difference in the performance of Experimental groupl, Experimental group 2 and control group

(ii) Experimental 1 group showed greater understanding of the human digestive system than Experimental group 2 and control group.

(iii) There is no gender difference in the performance of male and female students of Experimental group 1 and Experimental group 2

\section{Discussion of Results}

The result of the analysis of hypothesis one on the performance of students taught biology using computer assisted instructional packages (Exp1), students taught biology using a model (Exp2) and those taught with conventional classroom instruction. The result indicated a significant difference in favour of the students in the experimental groups. Scheffe test used as post hoc screening test to locate the observed significant difference indicatı $d$ that there was significant difference between the performances of students exposed is the two experimental groups. It is to be noted that students exposed to computer assisted instructional packages did better than those taught using the model as reflected in higher group mean. Furthermore, between the two experimental groups and the control group (conventional group) significant differences were established in favour of the two experimental groups.

These findings agree with earlier findings of some researchers which revealed that CAIP improved student's academic performance in science than traditional teaching methods which is teacher centered. (Wilder, 2006; Liao, 2007; Ragasa, 2008; Hançer \& Yalçın, 2009; \& Serin, 2011). These results also disagree with the earlier findings of Bayraktar (2001), Alacapınar (2003) \& Çetin (2007). which revealed that there is no significant difference in the academic performance of students exposed to CAI and those exposed to traditional teaching methods.

The influence of gender on the academic performance of students in biology when taught with CAIP was examined using hypotheses two. The result of the analysis of t-test showed no significant gender difference for learners exposed to CAIP. This finding 
agrees with the earlier results of Umar (2011) and Wushishi and Chado (2010) which revealed that there is no significant difference in the performance of male and female students in science concepts. This finding disagree with the result of Chinweze (2007) which showed that male students perform better than female students in science and technology concepts. Therefore, gender has no effect on academic performance.

The influence of gender on the academic performance of students in biology when taught with instructional model was examined using hypotheses three. The result of the analysis of t-test showed no significant gender difference for learners taught using model. This finding agrees with the earlier findings of Olowe (2009) and Yaki (2006) which revealed that there is no significant difference in the performance of male and female students taught with instructional model. It will probably be right to infer that gender has no effect on academic performance.

\section{Conclusion}

Based on the findings of this research work, the following conclusions were drawn:

- Students in the experimental group 1 and experimental group 2 perform better than those in the control group.

- experimental group 1 perform better than experimental group 2. This can be attributed to the novel nature of the CAIP in the school setting.

- CAIP and Model are not gender biased in learning.

\section{Recommendations}

Based on the findings of this study, the following recommendations are made:

- computer assisted instructional packages should be developed for use within the Nigerian school systems.

- Teachers should be encouraged to use models for teaching and learning as well as improvise in the absent of realia or real objects.

- Workshops on production and utilization of instructional materials especially computer aided instructional packages and models should be organized.

\section{References}

Ardac, D. (2005). Using static and dynamic visuals to represents chemical change at molecular level. International journal of science education vol. 27 (2)

Alacapinar, F. G. (2003). The effects of traditional education and education via computer on the students of Eurasin. Journal of Educational Research winter (10): 40-45.

Cetin U. (2007). A comparison of traditional teaching and the computer assisted education software based on ARCS motivation model in accordance with students; achievement and permanence of learning. Gazi University, Master's Degree, Department of Computer Education and instructional Technology. Ankara. 
Chinweze, F. O. (2007). The relative effectiveness of projected and non-projected media in the teaching of Biology in secondary school in Minna, Niger state. An unpublished M.Tech. thesis, federal University of technology Minna.

Dantani, I. W. \& Chado, A. M., (2010) Effects of teachers qualification on gender mathematical and problem solving abilities of secondary school chemistry students in Niger state Nigeria. Journal of arts and education, 4 (1):130 - 139.

Federal Republic of Nigeria, (2004). National policy on Education. Lagos: Federal Government press.

Gambari, A. I. (2010). Effectiveness of computer-assisted instructional package in cooperative settings on senior secondary school students' performance in physics, in Minna. Unpublished $\mathrm{PhD}$ dissertation University of Illorin, Nigeria

Gbodi, E. B. (1999). Visual imagery on learning outcomes of contour map reading. Journal of Science, Technology and Mathematics Education, 2 (1): 30-37.

Hançer, A. H., \& Yalçın, N. (2009). The effect of "computer-based learning based upon the constructivist approach in science education" on problem solving skills. University of Gazi, Faculty of Education Journal, 29 (1): 55-72.

Ibrahim, K. B. (2008) Construction and validation of the models of human digestive system for the teaching and learning biology in secondary schools in Minna Metropolis. Unpublished undergraduate project department of science education, Federal University of Technology Minna

Liao, Y. C. (2007). Effects of computer-assisted instruction on students' achievements in Taiwan: A meta analysis. Computer and Education, 48: 216-233

Njoku, Z. C. (2002). Enhancing girl's acquisition of science process skills in coeducational schools: An experience with sex grouping for practical chemistry. Journal of science teachers association of Nigeria, 37 (1\&2): 69-75

Olatunji A. B. (2008) Effects of combining computer animation, modeling and lecture method on the achievement of students in senior secondary school mathematics in Minna.

Olowe, T. T. (2009). Effects of computer animation and instruction model on the Performance of students in senior secondary students biology in Minna, Niger State, Nigeria. Unpublished Bachelor of Technology, Project, Department of Science Education, Federal University of Technology, Minna, Nigeria.

Özmen, H. (2004). Learning theories in science instruction and technology-assisted constructivist lea ning. The Turkish Online Journal of Educational Technology (TOJET), 3 (1): Article 14

Ragasa, C. Y. (2008). A comparison of computer-assisted instruction and the traditional method of teaching basic statistics. Journal of Statistics Education, 16 (1): Retrieved on November $21^{\text {st }}, 2011$ from http://www.amstat.org/publications

Serin, O. (2011). The effects of the computer-based instruction on the achievement and problem solving skills of the science and technology students. The Turkish Online Journal of Educational Technology, 10 (1): 183 - 2001.

Umar, A. A. (2011). Effects of biology practical activities on students process skills Acquisition in Minna Niger state. Journal of Science, Technology, Mathematics and Education (JOSMED), 7 (2).

Wilder, D. M. (2006). A field test of CAI software: Introduction to electricity. Unpublished Master's Thesis California University, Dominguez Hills 
Yaki, A. A. (2006). The construction and validation of male and female urinogenital system for Biology instruction in senior secondary school. Unpublished undergraduate project, science education department, federal university of technology Minna.

Yaki, A. A. (2011). Effects of computer animation and guided inquiry on secondary school students learning outcome in biology. Unpublished M.Ed thesis University of Abuja, Nigeria. 